\title{
Extended Half-life rFVIII for the Treatment of Hemophilia A: Drugs Consumption and Patients' Perspective
}

\author{
Daniela Paola Roggeri ${ }^{1}$, Ezio Zanon ${ }^{2}$, Chiara Biasoli ${ }^{3}$, Alessandro Roggeri ${ }^{1}$ \\ ProCure Solutions, Nembro (Bergamo), Italy \\ 2 Centro Emofilia, UOSD Coagulopatie, Azienda Universitaria Ospedaliera di Padova, Italy \\ 3 Centro Emofilia, UOC Medicina Trasfusionale, Dipartimento di Patologia Clinica, Ospedale Bufalini Cesena, Azienda Sanitaria \\ della Romagna, Italy
}

\begin{abstract}
Prophylaxis is recognized as the most effective treatment regimen for patients with severe hemophilia A. Prophylaxis with standard half-life (SHL) FVIII products requires frequent intravenous administrations, at least two-three times per week. Frequency of injections is reported as one of the major obstacles to adherence to treatment and caused impairment in quality of life (QoL) and possible clinical implications. The extended half-life (EHL) rFVIII products recently reimbursed by Italian National Health Service (NHS), give the possibility of prophylactic dosage regimens characterized by reduced administration frequency with the potential to increase adherence to therapy and to improve QoL and clinical outcomes. Based on the approved dosing regimens the minimum and maximum number of administrations per year and the annual consumption for the marketed EHL rFVIII products were estimated. Compared to Adynovi ${ }^{\circledR}$ and Elocta ${ }^{\circledR}$, Jivi ${ }^{\circledR}$ is the drug associated with the lowest number of administrations per year while versus Esperoct ${ }^{\mathbb{B}}$ is associated to a slightly higher maximum number of administrations per year. Furthermore, $\mathrm{Jivi}^{\circledR}$ has an annual mean consumption per kg lower than Adynovi ${ }^{\circledR}$, Elocta ${ }^{\circledR}$ and Esperoct $^{\circledR}(-24 \%,-27 \%$ and $-22 \%$, respectively). The contemporary reduction of number of injections per year and the lower annual mean consumption (IU) represent important benefits for the patient. From the economic point of view, at the prices published in Italian Official Journal, Jivi ${ }^{\circledR}$ weighted average annual expenditure per patient is $26 \%$ lower than Adynovi ${ }^{\circledR}$ and $29 \%$ lower than Elocta $^{\circledR}$ and a saving is possible even considering a $10 \%$ increase in Jivi ${ }^{\circledR}$ 's price per IU versus comparators. Among the EHL rFVIII concentrates Jivi ${ }^{\circledR}$ appears to be more suitable to cover patients' needs due to the possibility to adopt different dosage regimens (up to every 7 days) and is associated with the lowest average annual consumption per patient allowing a more predictable budget forecast and overall reducing the NHS expenditure.
\end{abstract}

\section{Keywords}

Hemophilia A; extended half-life; FVIII; Prophylaxis

\section{INTRODUCTION}

Hemophilia A is a rare, congenital, X-linked bleeding disorder caused by an absence or deficiency of clotting factor VIII (FVIII) [1]. The worldwide incidence of hemophilia A is approximately 1 case per 5,000 males, with approximately one third of affected individuals not having a family history of the disorder. The prevalence of hemophilia A varies with the reporting country, with a range of 5.4-14.5 cases per 100,000 males [2].

The symptoms consist of more or less severe hemorrhages, as a result of trauma, surgical procedures, or apparently spontaneous internal bleeding. This one most likely occurs into the joints (hemarthrosis), where over the long-term it leads to progressive and irreversible hemophilic arthropathy, but may also occurs into muscles, soft tissues and other sites (e.g. central nervous system) with potentially life-threatening consequences and not least drastic impairment in the individual's quality of life (QoL) [1]. The severity of bleeding phenotype depends on the extent of FVIII deficiency, or rather on the residual amount of FVIII plasma concentration, which classifies the disease as mild (FVIII ranges between 6 and $40 \mathrm{IU} / \mathrm{dL}$ ), moderate (FVIII from 1 to $5 \mathrm{IU} / \mathrm{dL}$ ), and severe (FVIII $<1 \mathrm{IU} / \mathrm{dL})[1]$.

Corresponding author Alessandro Roggeri alessandro.roggeri@procuresolutions.it Received: 6 May 2020 Accepted: 3 June 2020 Published: 16 June 2020 
The main treatment option for hemophilia A patients is a replacement therapy based on intravenous administration of FVIII concentrates. Two strategies are available: on-demand treatment, consisting in the treatment of an ongoing hemorrhage, or prophylaxis, consisting in long-term, regular infusions in order to prevent bleedings [1,3-5]. FVIII concentrates can be either plasma-derived or recombinant and recombinant FVIII (rFVIII) concentrates may exhibit standard (SHL) or extended half-life (EHL). The present analysis aims to identify possible advantages associated to the prophylactic use of EHL rFVIII products in the treatment of severe hemophilia A.

\section{UNMET MEDICAL NEED}

Prophylaxis is recognized as the most effective treatment regimen in order to prevent spontaneous hemarthroses, preserve healthy joints, reduce long-term hemophilic arthropathy and improve QoL. Nevertheless, it can show some critical issues resulting from the main characteristics of the SHL rFVIII concentrates.

Due to an average FVIII half-life of about 8-12 hours [1], prophylaxis with SHL FVIII products requires frequent intravenous administrations, at least two-three times per week on non-consecutive days, or every other day [6-8]. It had been demonstrated that the burden of frequent injections related to prophylaxis with SHL rFVIII concentrates was one of the major obstacles to adherence to treatment and caused impairment in QoL both in adolescents and adults $[9,10]$. EHL rFVIII products, giving the possibility of prophylactic dosage regimens characterized by reduced administration frequency, can favor the prophylaxis over the ondemand treatment, increase adherence to therapy and improve QoL [11].

A recent survey based on expert meeting and focus groups across Germany, Austria and Switzerland on adult hemophilia patients and parents of hemophilic children was conducted in order to better understand patients' expectations and concerns regarding EHL concentrates [12]. 743 adults and 262 parents of children affected by hemophilia participated to the survey; the majority of patients had hemophilia A (84.5\%), were severely affected $(73.7 \%)$, received regular prophylaxis $(57 \%)$ and used a recombinant product $(60.2 \%)$.

About $26 \%$ of patients/parents with hemophilia A were not aware regarding the correct half-life of their rFVIII concentrate. Expectations from new EHL products were less frequent injections (55.2\%), better efficacy (32.1\%) and safety, with no side effects (15.7\%). Even if patients were satisfied about their current treatment, overall the $59.5 \%$ of patients would be willing to switch to EHL products if they have the same safety profile of the current treatment. The main reason for willingness to switch to new EHL concentrates was prolonged dosing interval $(87.1 \%)$, while reasons for not willing to switch were fear of inhibitor development $(71.4 \%)$ and concerns on uncertain safety $(60.9 \%)$. In order to decide for the switch patients and parents would like to receive more information about half-life $(84.4 \%)$, possible side effects $(81.3 \%)$ and efficacy $(77 \%)$.

Mahlangu et al. [13], analyzed the published evidences of the new and upcoming rFVIII products in order to identify and propose a clear definition for the classification of "EHL rFVIIIs". Based on the proposed criteria (designed with technology to extend circulating biological half-life; demonstration of difference from a standard rFVIII comparator for the majority of patients according to proposed "biodifference" criteria based on the lower limit of the $90 \%$ CI for the area under the curve ratio being above the Food and Drug Administration - FDA/European Medicines Agency - EMA cut-off for bioequivalence, 1.25 or 125\%; having a half-life ratio of 1.3 or higher, based on modelling), Adynovi ${ }^{\circledR}$ (Baxalta Innovations $\mathrm{GmbH})$, Elocta $^{\circledR}$ (Swedish Orphan Biovitrum AB), Esperoct ${ }^{\circledR}$ (Novo Nordisk A/S) and Jivi ${ }^{\circledR}$ (Bayer AG) were identified as the only currently approved EMA drugs that can be considered as having an EHL.

\section{EFFICACY OVERVIEW}

\section{Adynovi $^{\circledR}$}

Adynovi $^{\circledR}$ (rurioctocog alfa pegol) is a full-length rFVIII chemically modified with 1-2 per $20 \mathrm{kDa}$ branched polyethylene glycol (PEG) approved by EMA for the treatment and prophylaxis of bleeding in patients with hemophilia A at least 12 years old. Recommended dosage for routine prophylaxis is 40-50 IU/kg twice-weekly (3-4 days interval); mean terminal halflife is 14-16 hours [14]. The safety and efficacy of Adynovi ${ }^{\circledR}$ were evaluated in a multicenter, open-label, phase II/III study conducted in 137 previously treated patients affected by severe 
hemophilia A who were aged 12 to 65 years [15]. The prophylactic regimen was administered for 50 or more exposure days or six months. Of these patients, 120 were treated in prophylaxis (45 IU/kg twice-weekly) and 17 were treated on-demand (10-60 IU/kg). The median (Q1; Q3) annualized bleeding rate (ABR) estimated from a negative binomial model in patients treated in prophylaxis was $1.9(0.0 ; 5.8)$ and $39.6 \%$ of compliant subjects had no bleeding episodes. No unexpected adverse events emerged in the study and there was no evidence of development of inhibitors in any patient.

\section{Elocta $^{\circledR}$}

Elocta $^{\circledR}$ (efmoroctocog alfa) is a B domain deleted (BDD) rFVIII Fc fusion protein (rFVIIIFc) approved for the treatment and prevention of bleeding in patients of all ages with haemophilia A. Forecasted dosing schedules in prophylaxis are $50 \mathrm{IU} / \mathrm{kg}$ every 3-5 days with the possibility to adjust the dose on the basis of patient's response in the interval $25-65 \mathrm{IU} / \mathrm{kg}$; mean terminal half-life is 19 hours [14].

The safety, efficacy and pharmacokinetics of Elocta ${ }^{\circledR}$ were evaluated in a multicenter, open-label, partially randomized phase III study conducted in 165 previously treated patients aged $\geq 12$ years affected by severe hemophilia A [16]. The study had 3 treatment arms: individualized prophylaxis (25-65 IU/kg every 3-5 days, $n=118$ ), weekly prophylaxis (65 IU/ $\mathrm{kg} /$ week, $\mathrm{n}=24)$ and episodic treatment of acute bleeding $(10-50 \mathrm{IU} / \mathrm{kg}, \mathrm{n}=23)$. The median duration of treatment ranged between 28 and 32.1 weeks, depending on the arm of treatment.

The median $(95 \% \mathrm{CI})$ ABRs estimated from a negative binomial regression model were $2.9(2.3-3.7)$ for patients in the individualized prophylaxis arm and $8.9(5.5-14.5)$ for those in the weekly prophylaxis arm. The median (IQR) observed ABRs were 1.6 (0.0-4.7) for patients in the individualized prophylaxis arm and $3.6(1.9-8.4)$ for those in the weekly prophylaxis arm. No bleeding episodes were experienced in $45.3 \%$ and $17.4 \%$ of subjects in the individualized prophylaxis arm and in the weekly prophylaxis arm, respectively.

Adverse events were consistent with those expected in this population; no subjects developed inhibitors.

\section{Esperoct $^{\circledR}$}

Esperoct $^{\circledR}$ (turoctocog alfa pegol) is a rFVIII featuring a $40 \mathrm{kDa}$ PEG conjugated to a $\mathrm{B}$ domain truncated (BDT) FVIII via site-direct glycoPEGylation, approved by EMA for the treatment and prophylaxis of bleeding episodes in adolescent ( $\geq 12$ years) and adult patients with hemophilia A. Starting dose is $50 \mathrm{IU} / \mathrm{kg}$ every 4 days; adjustments of doses and administration intervals may be considered based on achieved factor VIII levels and individual bleeding tendency, but the maximum single dose must not exceed $75 \mathrm{IU} / \mathrm{kg}$. Mean terminal half-life is 18.4 hours [17].

The safety, pharmacokinetics and clinical efficacy of Esperoct ${ }^{\circledR}$ were evaluated in a phase III, multinational, open-label, non-randomized trial conducted in 186 previously treated patients ( $n=175$ in the prophylaxis arm and $n=12$ in the on-demand arm) aged $\geq 12$ years with severe hemophilia A [17]. Patients on prophylaxis received one dose of $50 \mathrm{IU} / \mathrm{kg}$ of Esperoct ${ }^{\mathbb{R}}$ every fourth day (twice-weekly dosing was allowed for patients at the discretion of the investigator). The mean duration in the prophylaxis arm was 299 days.

During the trial, 7 patients in the prophylaxis arm withdrew within the first month of treatment; an ABR of 24 was imputed for them. Overall, the imputed median (IQR) ABR was 1.33 (0.0-4.6), while the median (IQR) ABR estimated on observed data without imputation was $1.18(0.0-4.3)$. Among patients on prophylaxis, the $40 \%$ had no bleeding episodes during the trial.

One patient developed inhibitory antibodies against FVIII after 93 exposure days of Esperoct $^{\circledR}$ therapy.

\section{Jivi $^{\circledR}$}

Jivi $^{\circledR}$ (damoctocog alfa pegol) is a BDD rFVIII with site-specific attachment of a single dual-branched $60 \mathrm{KDa}$ PEG, approved by EMA for the treatment and prophylaxis of bleeding in previously treated patients $\geq 12$ years of age with haemophilia A. Recommended schedules in prophylaxis are 45-60 IU/kg every 5 days, $60 \mathrm{IU} / \mathrm{kg}$ every 7 days and 30-40 IU/kg twice a week; mean terminal half-life is about 19 hours [18].

The safety and efficacy of $\mathrm{Jivi}^{\circledR}$ were evaluated in a phase II/III multicenter, partially randomized, open-label, 36-week trial conducted in 134 previously treated patients aged 12-65 years affected by severe hemophilia A [18]. Twenty patients received on-demand therapy and 114 patients entered the prophylaxis arm of the study. During an initial run-in 
period of 10 weeks, all patients in prophylaxis were treated at a dosage of $25 \mathrm{IU} / \mathrm{kg}$ twice a week. Based on the number of bleedings experienced during the run-in period, patients were then assigned to different prophylaxis arms: 86 patients who experienced a maximum of 1 bleeding were randomized $1: 1$ to receive 45-60 IU/kg every 5 days $(n=43)$ or $60 \mathrm{IU} / \mathrm{kg}$ every 7 days $(n=43) ; 13$ patients stayed in the twice-weekly prophylaxis arm and received $30-40 \mathrm{IU} / \mathrm{kg}$ because of $>1$ bleed during the run-in period (two times per week, not eligible for randomization); 11 patients stayed in the twice-weekly prophylaxis arm and received 30-40 IU/kg because the randomization arms were full (two times per week, eligible but not randomized).

During the subsequent study weeks 11-36, the median (Q1; Q3) observed ABR for patients treated twice-weekly not eligible for randomization $(n=13)$ improved after dose increase from $17.4(14.3 ; 26.0)$ to $4.1(2.0 ; 10.6)$. Median (Q1; Q3) ABR for patients randomized to every 5 days treatment $(\mathrm{n}=43)$ was $1.9(0.0 ; 4.2)$, similar to patients eligible for the randomization but continuing the twice-weekly treatment $(n=11)$. Median (Q1; Q3) ABR for patients randomized to every 7 days treatment who completed the study without modify their starting dosing frequency $(n=32 / 43)$ was $0.96(0.0 ; 4.3)$. A median ABR of 2.1 bleeds was reported in the 110 patients in the entire prophylaxis arm. No bleeding episodes were experienced in $44.2 \%$ and $50.0 \%$ of subjects in the every 5 days and every 7 days treatment arm, respectively. No evidence of development of FVIII inhibitors emerged during the study.

Patients who completed the previous study were offered to continue the treatment with $\mathrm{Jivi}^{\circledR}$ in an optional extension study. Treatment regimen options were the same as in the main study; patients could either continue their previous regimen or change to another prophylaxis regimen, as needed.

Interim data (data cut-off January 2018) from 107 patients who entered the extension study receiving prophylaxis treatment indicated that bleed control was well maintained for up to $>5$ years. ABR varied according to the prescribed prophylaxis regimen: patients who remained in the every-7-days group reported a median $(\mathrm{Q} 1$; Q3) ABR of $0.7(0 ; 1.6)$, while in patients who changed regimen (variable frequency group) the median (Q1; Q3) ABR was 3.1 $(1.2 ; 6.2)$. If we consider the total prophylaxis arm, the median (Q1; Q3) ABR was 1.6 (0.3; 4.6). Among patients treated on prophylaxis, the $20.6 \%$ experienced zero bleedings during the entire extension study and the $51.0 \%$ had no bleedings in the last six months [19].

\section{DRUG CONSUMPTION ANALYSIS}

Based on the approved dosing regimens, it is possible to estimate the minimum and maximum number of administrations per year and the annual consumption with the marketed EHL rFVIII products (Table 1) [20-23].

As reported in Table I, with respect to Adynovi ${ }^{\circledR}$ and Elocta $^{\circledR}, \mathrm{Jivi}^{\circledR}$ is the drug associated with the lowest number of administrations per year (52-104 vs 104 of Adynovi $^{\circledR}$ and 73-122 of Elocta $\left.{ }^{\circledR}\right)$. Compared to Esperoct ${ }^{\circledR}$, instead, $\mathrm{Jivi}^{\circledR}$ is associated to a slightly higher maximum number of administrations per year (104 vs 91). However, in the pivotal trial, the majority of patients completed the study being treated every $5-7$ days $(75.5 \%$ vs $24.5 \%$ of patients being

\begin{tabular}{|c|c|c|c|c|c|c|c|c|c|c|}
\hline \multirow{2}{*}{ Drug } & \multirow{2}{*}{$\begin{array}{l}\text { Posology in SPC } \\
\text { (prophylaxis) }\end{array}$} & \multicolumn{3}{|c|}{$\begin{array}{c}\text { Dosage in SPC } \\
(\mathrm{IU} / \mathbf{k g})\end{array}$} & \multicolumn{3}{|c|}{$\begin{array}{c}\text { Annual } \\
\text { administrations (n) }\end{array}$} & \multicolumn{3}{|c|}{$\begin{array}{l}\text { Annual consumption } \\
\text { (IU/kg) }\end{array}$} \\
\hline & & Min & Mean'1 & Max & Min & Mean' ${ }^{1}$ & Max & Min & Mean ${ }^{1}$ & Max \\
\hline $\begin{array}{l}\text { Adynovi }^{\circledR} \\
\text { (ruriocotcog alfa } \\
\text { pegol) }\end{array}$ & 40-50 IU/kg twice a week & 40 & 45 & 50 & 104 & 104 & 104 & 4,160 & 4,680 & 5,200 \\
\hline $\begin{array}{l}\text { Elocta }^{\circledR} \\
\text { (efmoroctocog alfa) }\end{array}$ & 25-65 IU/kg every 3-5 days & 25 & 45 & 65 & 73 & 98 & 122 & 1,825 & 4,878 & 7,930 \\
\hline $\begin{array}{l}\text { Esperoct }^{\circledR} \\
\text { (turoctocog } \\
\text { alfa pegol) }\end{array}$ & $50 \mathrm{IU} / \mathrm{kg}$ every 4 days & 50 & 50 & 50 & 91 & 91 & 91 & 4,550 & 4,550 & 4,550 \\
\hline \multirow{3}{*}{$\begin{array}{l}\mathrm{Jivi}^{\circledR} \\
\text { (damoctocog } \\
\text { alfa pegol) }\end{array}$} & 45-60 IU/kg every 5 days & 45 & 53 & 60 & 73 & 73 & 73 & 3,285 & 3,833 & 4,380 \\
\hline & $60 \mathrm{IU} / \mathrm{kg}$ every 7 days & 60 & 60 & 60 & 52 & 52 & 52 & 3,120 & 3,120 & 3,120 \\
\hline & 30-40 IU/kg twice a week & 30 & 35 & 40 & 104 & 104 & 104 & 3,120 & 3,640 & 4,160 \\
\hline
\end{tabular}

Table I. Dosages, number of administrations and annual consumption based on European approved SPCS [20-23]

${ }^{1}$ Mean values are estimates as average between min and max 
treated twice-weekly), supporting the concrete possibility to reduce the frequency of infusion. As previously shown, the prolonged dosing interval for the prophylactic treatment allowed for $\mathrm{Jivi}^{\circledR}$ can contribute to improve the compliance to treatment and QoL of patients.

In addition, from the analysis of the annual consumption, Jivi ${ }^{\circledR}$ has an annual mean consumption per kg lower than Adynovi ${ }^{\circledR}(4,680 \mathrm{IU} / \mathrm{kg})$, Elocta ${ }^{\circledR}(4,878 \mathrm{IU} / \mathrm{kg})$ and Esperoct ${ }^{\circledR}$ $(4,550 \mathrm{IU} / \mathrm{kg})$. The contemporary reduction of number of injections per year and the lower annual mean consumption represent an important benefit for the patient.

The advantage in term of annual drug consumption of Jivi ${ }^{\circledR}$ appears also clearer in Figure 1, where the average annual consumption for a $70 \mathrm{~kg}$ patient for each EHL rFVIII product is reported.

$\mathrm{Jivi}^{\circledR}$ allows a reduction in average annual drug consumption per patient of $-27 \%$ vs Eloc$\mathrm{ta}^{\circledR},-24 \%$ vs Adynovi ${ }^{\circledR}$ and $-22 \%$ vs Esperoct ${ }^{\circledR}$; the difference is much wider if also SHL rFVIII products are considered (e.g. $-28 \%$ versus Afstyla ${ }^{\circledR}$ ), enabling possible economic savings for the National Health Service (NHS) (Figure 2).

Additionally, among products that have been approved with a dose range (therefore all excluded Esperoct $\left.{ }^{\circledR}\right)$, Jivi $^{\circledR}$ is the only one to provide regimens with a unique narrow range of variability between minimum and maximum rFVIII consumption, enabling health authorities to make a more precise expenditure forecasting compared with all others SHL and EHL rFVIII products.

On the basis of the approved dosing regimens, in fact, the maximum variability allowed for $\mathrm{Jivi}^{\circledR}$ versus mean value in terms of consumption per patient per year is $\pm 14 \%$, for Elocta ${ }^{\circledR}$ it is $\pm 62.5 \%$, for Adynovi ${ }^{\circledR} \pm 11 \%$ (but with an expected average consumption of about 80,000 IU/year/patient higher than $\mathrm{Jivi}^{\circledR}$ ) and for Esperoct ${ }^{\circledR} 0$ (but with an average consumption of about 70,000 IU/year/patient higher than Jivi ${ }^{\circledR}$ ).

The abovementioned analysis and considerations need to be further evaluated in real-life condition according to current clinical practice.

\section{PATIENTS’ REPORTED OUTCOMES AND QUALITY OF LIFE}

\section{$\mathrm{Jivi}^{\circledR}$}

EHL rFVIII products such as $\mathrm{Jivi}^{\circledR}$ offer the potential for increased protection against bleeds while requiring less frequent infusions and IU consumption. A recent analysis aimed to evaluate patients reported outcomes regarding the benefit of the treatment with an EHL rFVIII therapy with $\mathrm{Jivi}^{\circledR}[24,25]$.

Adult patients participating in the PROTECT VIII extension study were invited to take part in the study, based on telephone interviews using a semi-structured interview guide. Most relevant topics investigated included treatment-related issues and impact on health-related

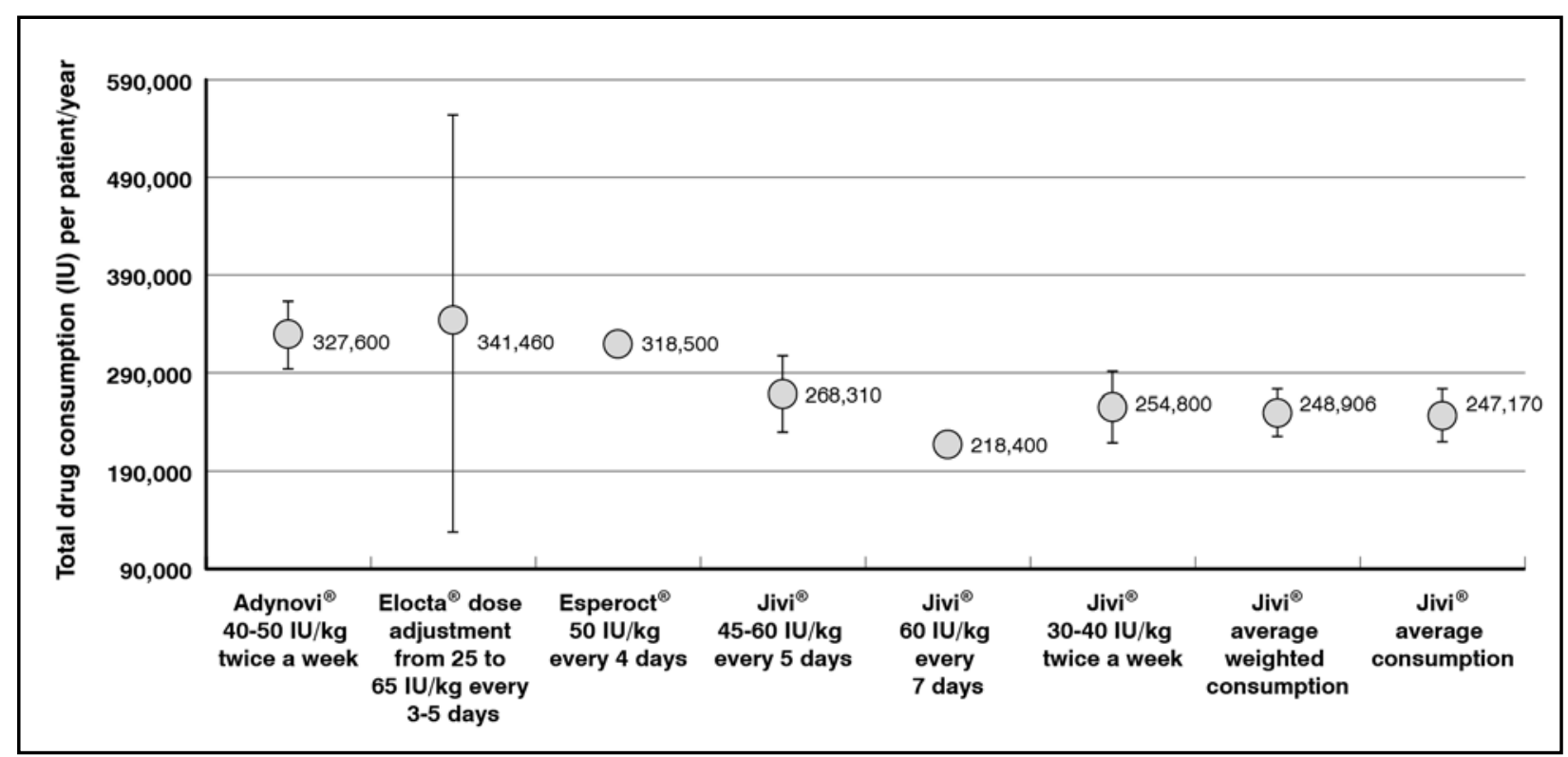

Figure 1. EHL rFVIII products' average annual drug consumption (IU, for a $70 \mathrm{~kg}$ patient)

Average weighted consumption is calculated on the basis of patients treated with each approved dosage regimen in clinical trial 


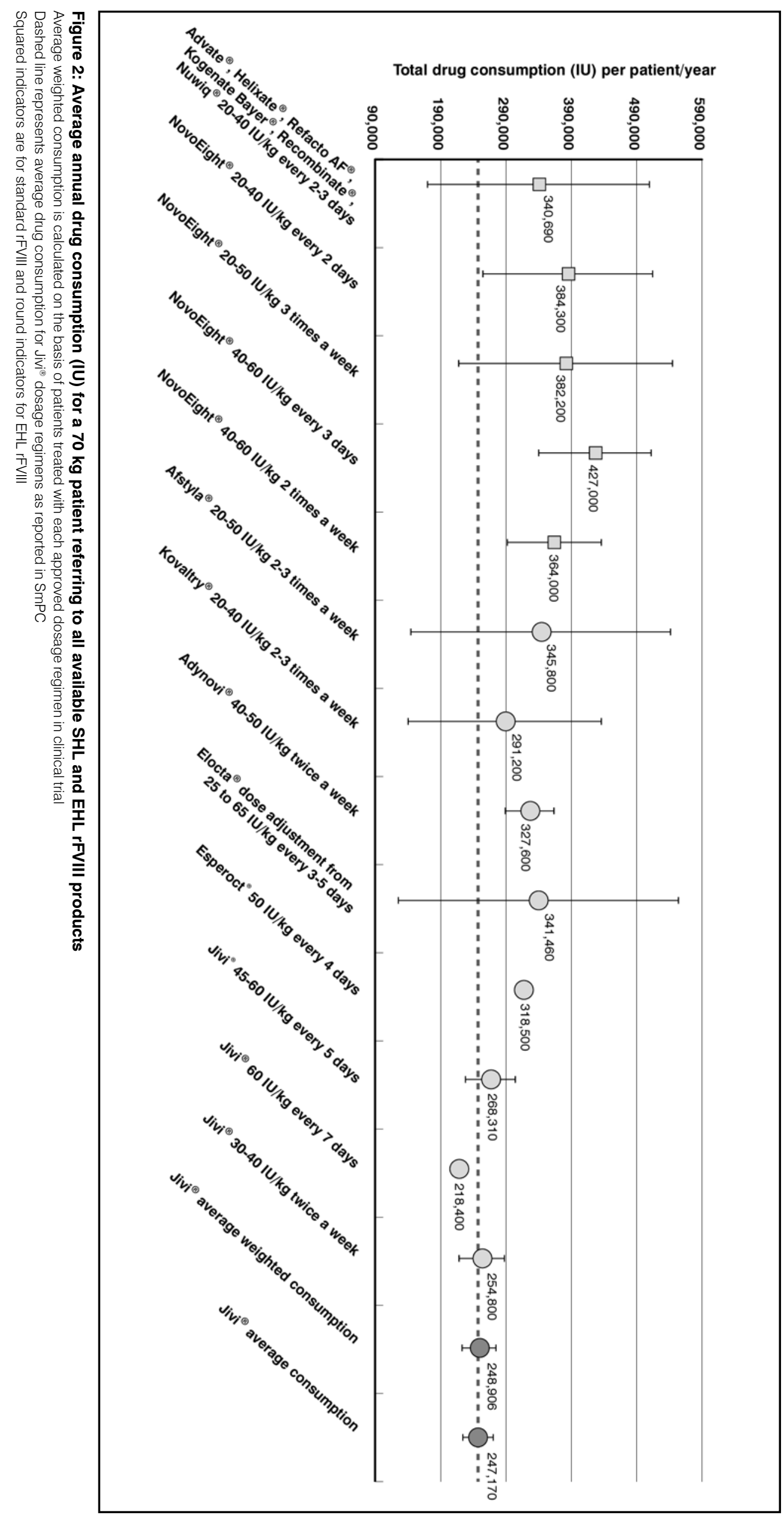


QoL (HRQoL). All participants had been receiving $\mathrm{Jivi}^{\circledR}$ for at least one year prior to their interview.

Reduced frequency of treatment administration was one of the most frequently reported drivers $(67 \%)$ of treatment satisfaction among patients with haemophilia $\mathrm{A}$, alongside efficacy. Less frequent infusions were also associated with benefits in terms of HRQoL (time taken to schedule and administer infusions, emotional benefits, physical benefits, consistency of factor coverage, participation in activities, and adherence), confirming the results of the survey previously presented. Details of patients' reported benefits highlighted in Wells et al analysis are detailed in Figure 3.

$\mathrm{Jivi}^{\circledR}$ provides patients extended dosing intervals with longer protection, improving confidence in treatment and reducing impact on activities of daily living.

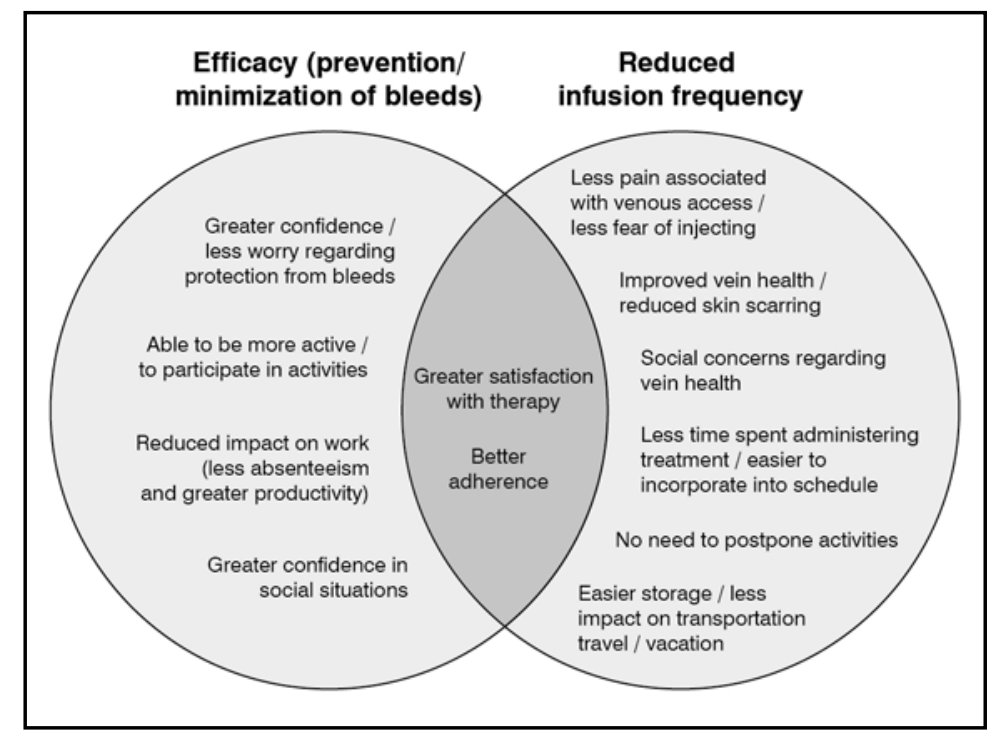

Figure 3. Key patient-reported benefits related to the treatment with Jivi ${ }^{\circledR}$. Modified from [24]

\section{Esperoct $^{\circledR}$}

One study has also been published recently regarding health related quality of life (HRQoL) and treatment satisfaction of patients with severe hemophilia A from two phase III trials evaluating the safety and efficacy of Esperoct ${ }^{\circledR}$ in pediatric, adolescent and adult patients with severe hemophilia A [26]. HRQoL was measured through the Haemo-QoL questionnaire in patients aged 4-16 years and through the Haem-A-QoL in those who were $\geq 17$ years. Treatment satisfaction was assessed by using the Hemo-Sat. At starting of the trials all patients reported a good overall HRQoL, but a little margin for improvement remains for any group; in fact an improvement in "Physical Health" and in overall hemophilia-specific HRQoL was observed in all age classes treated with Esperoct ${ }^{\circledR}$ in prophylaxis regimens while adults reported improvements also in school/work activities. Similarly, high level for treatment satisfaction were reported for both children and adults at baseline and an improvement was recorded at the end of the observation indicating a comparable or higher level of satisfaction with Esperoct ${ }^{\circledR}$ treatment. Treatment satisfaction resulted comparable between patients receiving the on-demand treatment and those in the prophylaxis arm.

\section{Elocta $^{\circledR}$}

The recent prospective, qualitative cohort study HOPE was developed to describe the expectations of patients with hemophilia (A and B) regarding the use in prophylaxis of EHL rFVIII products and if these expectations were realized using a follow-up analysis [27]. The study was conducted through two semi-structured interviews to 25 patients ( 23 with hemophilia A).

The results highlight that patients are intended to continue the treatment with EHL products and that the reduced frequency of administrations is perceived as a positive factor that decrease the impact of hemophilia on their lives. Even patients who did not reduce the frequency of administration perceived positive aspect of EHL treatment as a higher protection level and a lower number of bleeding occurred.

\section{ECONOMIC CONSIDERATIONS}

At the moment of the preparation of the manuscript, all the above mentioned EHL rFVIII products are reimbursed by Italian NHS except Esperoct ${ }^{\circledR}$. Considering their prices published on the Italian Official Journal, the differences in expenditure are reported in Figure 4.

At the prices published in Italian Official Journal Jivi ${ }^{\circledR}(0.70 € / \mathrm{IU}$ ex-factory [28]) weighted average annual expenditure per patient is $26 \%$ lower than Adynovi ${ }^{\circledR}(0.72 € /$ IU ex-factory [29]) and $29 \%$ lower than $\operatorname{Elocta}^{\circledR}(0.72 € /$ IU ex-factory [30]).

Considering that hidden discounts have been negotiated with Italian Medicines Agency (AIFA) for all the EHL products, a sensitivity analysis was conducted; this analysis, for any 


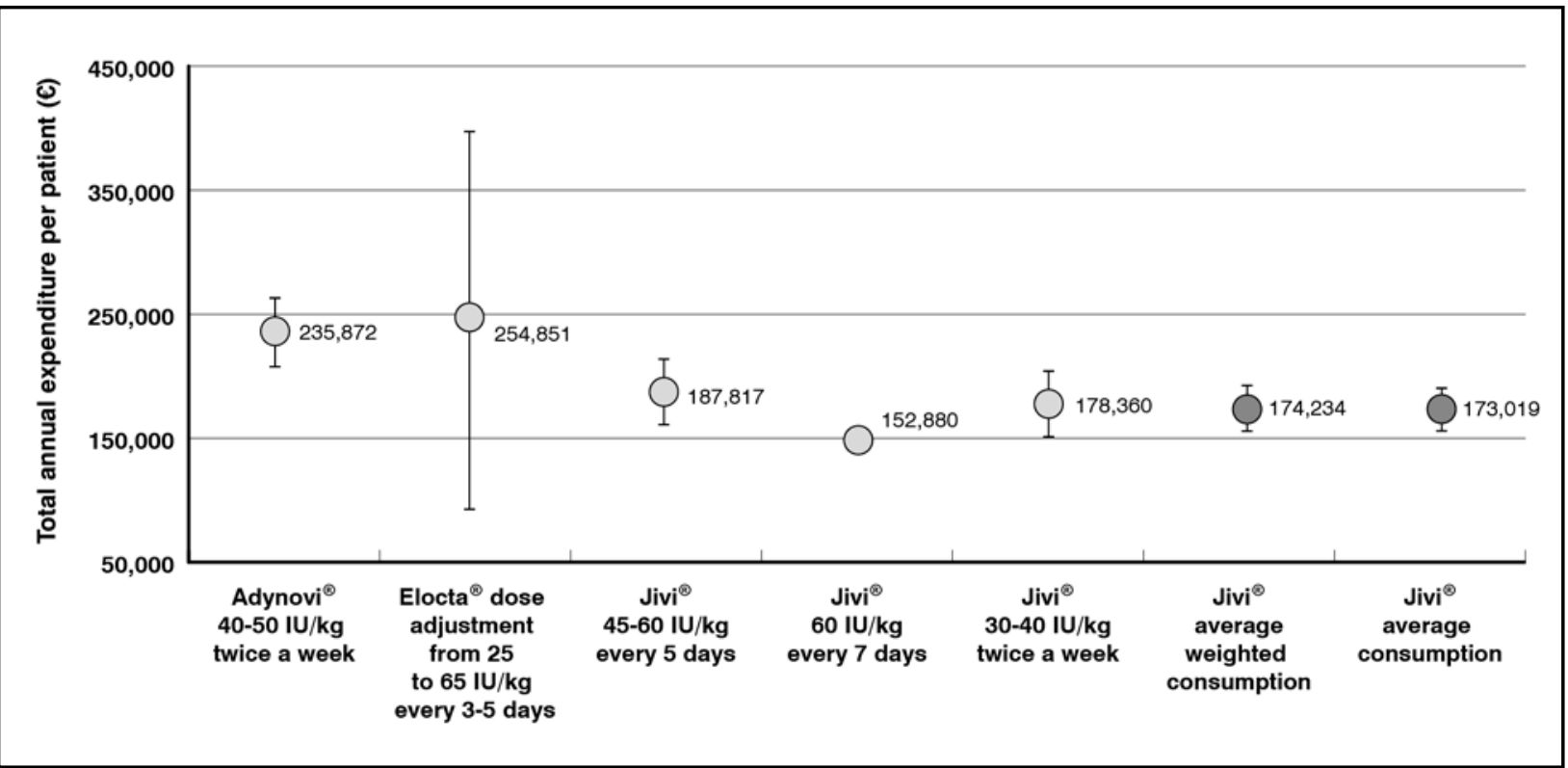

Figure 4. EHL rFVIII products' total annual expenditure (mean, minimum and maximum annual expenditure for a $70 \mathrm{~kg}$ patient) Average weighted consumption is calculated on the basis of patients treated with each approved dosage regimen in clinical trial

level of parity price per IU, results in a weighted average annual expenditure per patient for Jivi $^{\circledR} 24 \%$ lower than Adynovi $^{\circledR}$ and $27 \%$ lower than Elocta ${ }^{\circledR}$.

Even considering a $10 \%$ increase in Jivi ${ }^{\circledR}$ 's price (per IU) versus the same per IU price for Adynovi $^{\circledR}$ and Elocta $^{\circledR}$, the per patient annual expenditure for $\mathrm{Jivi}^{\circledR}$ remains $16 \%$ lower than Adynovi $^{\circledR}$ and $20 \%$ lower than Elocta ${ }^{\circledR}$.

About Esperoct ${ }^{\circledR}$, as the average per patient annual consumption is higher than Jivi ${ }^{\circledR}$ 's one, if we consider a possible per IU reimbursed price aligned with Jivi ${ }^{\circledR}$ 's one, it would result in a lower annual per patient cost for Jivi ${ }^{\circledR}$.

As above mentioned, the foreseen savings related to the use of Jivi ${ }^{\circledR}$ are due to the reduced consumption of drug and reduced frequency of administrations.

\section{CONCLUSIONS}

Novel EHL rFVIII products, being associated with a reduced number of administrations and a good risk-benefit profile, seem to have the potential to change treatment patterns of patients with severe hemophilia $\mathrm{A}$ also favoring the compliance to prophylaxis regimen.

Moreover, these new drugs cover a clinical unmet need in patients with a QoL affected by frequency of administrations and related impact on daily life, as already demonstrated in the analysis that evaluates reported outcomes for patients treated with Jivi ${ }^{\circledR}$ and HRQoL in patients treated with Esperoct ${ }^{\mathbb{R}}$.

Among the EHL rFVIII concentrates, only Jivi ${ }^{\circledR}$, based on the clinical trial results, got in the label the indication of one administration every 7 days. Jivi ${ }^{\circledR}$ appears to be more suitable to cover patients' needs due to the possibility to adopt different dosage regimens, which allow to obtain a personalized treatment pattern. Besides, Jivi ${ }^{\circledR}$ is associated with the lowest average annual consumption per patient addressing the Health Authorities' needs, allowing a more predictable budget forecast and overall reducing the NHS expenditure.

\section{Funding}

Financial support for editorial services was provided by Bayer.

\section{Conflicts of interest}

DPR e AR report financial support for editorial services from Bayer during the conduct of the study, and consultancy fees from Bayer outside the submitted work.

EZ has nothing to disclose.

CB reports personal fees from Bayer, CSL, BIO VIII, and Takeda, outside the submitted work. 


\section{REFERENCES}

1. Srivastava A, Brewer AK, Mauser-Bunschoten EP, et al; Treatment Guidelines Working Group on Behalf of The World Federation of Hemophilia. Guidelines for the management of hemophilia. Haemophilia 2013; 19: e1-47; https://doi.org/10.1111/j.1365-2516.2012.02909.x

2. Drelich DA. Hemophilia A. Medscape, 2019. Available at https://emedicine.medscape.com/article/779322overview\#a1 (last accessed January 2020)

3. RocinoA, CoppolaA, Franchini M, etal. Principles of treatment and update of recommendations for the management of haemophilia and congenital bleeding disorders in Italy. Blood Transfus 2014; 12:575-98; https://doi.org/10.2450/2014.0223-14 Colvin BT, Astermark J, Fischer K, et al; Inter Disciplinary Working Group. European principles of haemophilia care. Haemophilia 2008; 14: 361-74; https://doi.org/10.1111/j.1365-2516.2007.01625.x

4. Berntorp E, Boulyjenkov V, Brettler D, et al. Modern treatment of haemophilia. Bull World Health Organ 1995; 73: 691-701

5. Mancuso ME, Santagostino E. Outcome of Clinical Trials with New Extended Half-Life FVIII/IX Concentrates. $J$ Clin Med 2017; 6: E39; https://doi.org/10.3390/jcm6040039

6. Balkaransingh P, Young G. Novel therapies and current clinical progress in hemophilia A. Ther Adv Hematol 2018; 9: 49-61; https://doi.org/10.1177/2040620717746312

7. Schrijvers LH, Uitslager N, Schuurmans MJ, et al. Barriers and motivators of adherence to prophylactic treatment in haemophilia: a systematic review. Haemophilia 2013; 19: 355-61; https://doi.org/10.1111/hae.12079

8. Hacker MR, Geraghty S, Manco-Johnson M. Barriers to compliance with prophylaxis therapy in haemophilia. Haemophilia 2001; 7: 392-6; https://doi.org/10.1046/j.1365-2516.2001.00534.X

9. Richards M, Altisent C, Batorova A et al. Should prophylaxis be used in adolescent and adult patients with severe haemophilia? An European survey of practice and out- come data. Haemophilia 2007; 13: 473-9; https://doi. $\operatorname{org} / 10.1111 /$ j.1365-2516.2007.01478.x.

10. Jimenez-Yuste V, Auerswald G, Benson G, et al. Achieving and maintaining an optimal trough level for prophylaxis in haemophilia: the past, the present and the future. Blood Transfus 2014; 12:314-9; https://doi.org/10.2450/2014.0298-13

11. Von Mackensen S, Kalnins W, Krucker J, et al. Haemophilia patients' unmet needs and their expectations of the new extended half-life factor concentrates. Haemophilia 2017; 23: 566-74; https://doi.org/10.1111/hae.13221

12. Mahlangu J, Young G, Hermans C, et al. Defining extended half-life rFVIII-A critical review of the evidence. Haemophilia 2018; 24: 348-58; https://doi.org/10.1111/hae.13438

13. Lambert T, Benson G, Dolan G, et al. Practical aspects of extended half-life products for the treatment of haemophilia. Ther Adv Hematol 2018; 9: 295-308; https://doi.org/10.1177/2040620718796429

14. Konkle, BA, Stasyshyn, O, Chowdary, P, et al. Pegylated, full-length, recombinant factor VIII for prophylactic and ondemand treatment of severe hemophilia A. Blood 2015; 126: 1078-85; https://doi.org/10.1182/blood-2015-03-630897

15. Mahlangu J, Powell JS, Ragni MV, et al. Phase 3 study of recombinant factor VIII Fc fusion protein in severe hemophilia A. Blood 2014; 123: 317-25; https://doi.org/10.1182/blood-2013-10-529974

16. Giangrande P, Andreeva T, Chowdary P, et al. Clinical evaluation of glycoPEGylated recombinant FVIII: Efficacy and safety in severe haemophilia A. Thromb Haemost 2017; 117: 252-61; https://doi.org/10.1160/TH16-06-0444

17. Reding MT, Ng HJ, Poulsen LH, et al. Safety and efficacy of BAY 94-9027, a prolonged-half-life factor VIII. $J$ Thromb Haemost 2017; 15: 411-9; https://doi.org/10.1111/jth.13597

18. Lalezari S, Reding MT, Pabinger I et al. BAY 94-9027 Prophylaxis Is Efficacious and Well Tolerated for Up to $>5$ Years With Extended Dosing Intervals: PROTECT VIII Extension Interim Results. Haemophilia 2019; 25: 1011-9; https://doi.org/10.1111/hae.13853

19. Adynovi ${ }^{\circledR}$ - Summary of product characteristics. Available at: https://www.ema.europa.eu/documents/productinformation/adynovi-epar-product-information_it.pdf (last accessed January 2020)

20. Elocta $^{\circledR}$ - Summary of product characteristics. Available at: https://ec.europa.eu/health/documents/communityregister/2017/20170531138053/anx_138053_it.pdf (last accessed January 2020)

21. Esperoct ${ }^{\circledR}$ - Summary of product characteristics. Available at: https://www.ema.europa.eu/en/documents/productinformation/esperoct-epar-product-information_en.pdf (last accessed January 2020)

22. Jivi ${ }^{\circledR}$ - Summary of product characteristics. Available at: https://www.ema.europa.eu/documents/product-information/ jivi-epar-product-information_it.pdf(last accessed January 2020) 
23. Wells J, Kessabi S, Vashi P, et al. Patient Perspectives on the Value of Longevity of Protection and Reduced Infusion Frequency for Prophylactic Treatment of Hemophilia A. National Hemophilia Foundation Bleeding Disorders Conference. Orlando, 2018

24. Wells JR, Gater A, Marshall C, et al. Exploring the Impact of Infusion Frequency in Hemophilia A: Exit Interviews with Patients Participating in BAY 94-9027 Extension Studies (PROTECT VIII). Patient 2019; 12: 611-9; https://doi.org/10.1007/s40271-019-00374-x

25. Kearney S, Raffini LJ, Pham TP, et al. Health-related quality-of-life and treatment satisfaction of individuals with hemophilia A treated with turoctocog alfa pegol (N8-GP): a new recombinant extended half-life FVIII. Patient Prefer Adherence 2019; 13: 497-513; https:// doi.org/10.2147/PPA.S196103

26. Khair K, Pollard D, Harrison C, et al. How Patients view Extended half-life products: Impressions from real-world experience (The HOPE study). Haemophilia 2019; 25: 814-20; https://doi.org/10.1111/hae.13803

27. Agenzia Italiana Del Farmaco - AIFA. Determina 18 febbraio 2019. Classificazione, ai sensi dell'articolo 12, comma 5, della legge 8 novembre 2012, n. 189, dei medicinali per uso umano «Jivi» e «Pifeltro», approvati con procedura centralizzata. GU Serie Generale n.53 del 04-03-2019

28. Agenzia Italiana Del Farmaco - AIFA. Determina 3 gennaio 2020. Riclassificazione del medicinale per uso umano «Adynovi», ai sensi dell'articolo 8, comma 10, della legge 24 dicembre 1993, n. 537. GU Serie Generale n.14 del 18-01-2020

29. Agenzia Italiana Del Farmaco - AIFA. Determina 6 luglio 2016. Classificazione del medicinale per uso umano «Elocta», ai sensi dell'articolo 8, comma 10, della legge 24 dicembre 1993, n. 537. GU Serie Generale n.175 del 28-07-2016 